\title{
Research of Impact of COVID-19 on Clothing Industry Using Fama-French Five-Factor Model
}

\author{
Xinrong $\mathrm{Ji}^{1}{ }^{1,+}$, Keying $\mathrm{Li}^{2, \dagger}$, Zijie $\mathrm{Yu}^{3, \dagger}$ \\ ${ }^{1}$ Nanjing No.1 Middle School, Nanjing, 210004, China \\ 2 Dauntsey's School, Devizes, SN104HE, the U.K. \\ ${ }^{3}$ Shanghai Weiyu High School, Shanghai, 200231, China \\ *Corresponding author. Email: ericji@Stanford.edu \\ These authors contributed equally.
}

\begin{abstract}
As COVID-19 negatively affected the U.S. stock market, the performances of stocks vary from different industries. This research focused on the specific impact of the pandemic on the clothing industry specifically. The study used the Fama-French 5 factor model, which includes two other variables - RMW and CMA based on the Fama-French 3 factor model, including factors of return on the market, size of firms, and book-to-market values, to get the performance of stocks of the clothing industry. The data from a time before COVID-19, which was January 2019, to time during the pandemic, March 2021, is obtained from Kenneth R. French Data Library. The two sets, which are before and during the pandemic, of coefficients of all the five factors and $R_{i}-R_{f}$ are calculated using the model and compared with each other. The results show the change in the significance of three factors: value, profitability, and investment, which suggests that the performance of companies in the clothing industry is related to those three variables. In conclusion, investors should be careful with firms with low book-to-market ratios and those with low investments. Additionally, investors need to be cautious with firms that have robust profitability.
\end{abstract}

Keywords: Fama-French model, COVID-19, U.S. stock market, Clothing industry

\section{INTRODUCTION}

\subsection{Background}

The COVID-19 pandemic has severely disrupted global economic activity and lead to an unprecedented negative impact on the global economy. For example, sectors that have been the most severely affected rely on international travel, including air transport and accommodation.

In addition, this contagious infectious disease also affects the stock market. The impact on the stock market began on January 20, and in the following two weeks, global risk assets experienced a considerable adjustment. The Nasdaq Composite index fell by approximately 2,400 points in the four weeks from February 12 to March 11, 2020, but has since recovered to $13,756.33$ points as of June 2, 2021. In February 2020 - just before the global coronavirus pandemic, the Nasdaq Composite index stood at a little over 9,700 points.
On the other hand, the COVID-19 pandemic can result in fusing, stimulating the fusing mechanism. The fusing mechanism, known as the automatic suspension mechanism, refers to the suspension of trading measures adopted by the exchange to control risks when the volatility of the stock index reaches the specified fusing point. On the same day, here's a real-world example: the three major stock indexes plunged in pre-market trading, which fell more than $7 \%$ at the opening and triggered a fuse. In the end, the Dow closed at 20188.52 points, down $12.93 \%$; the S \& P 500 closed at 2386.13 points, down 11.98\%; the Nasdaq Composite Index closed at 6904.59 points, down $12.32 \%$. Moreover, the Dow slumped 2997.1 points throughout the day, falling back to the March 2017 level. In summary, those indexes were faced with the most terrible period in US stock history, and the whole stock market suffered from COVID-19 tremendously.

When it comes to asset pricing, it is fundamental to the adopted understanding of the wealth dynamics of an economy. This central importance has resulted in the 
extensive literature on asset pricing, much of it focusing on the economic factors that influence asset prices.

\subsection{Related Research}

The impact of the COVID-19 is of crucial importance, especially since its first outbreak happened in China, which is the main hub of foreign investment in Asia. Liu et al. evaluate the short-term impact using an event study method and panel fixed effect regressions. The result is that Asian countries experienced seriously negative returns on the stock market [1]. Cristofaro et al. evaluate the impacts on the Chinese stock market during covid-19 by fractional integration method. Two different indices - Shanghai Composite Index and Shenzhen Composite Index- are adopted to represent the stock market dynamic in China. This leads to the result that stock markets in China have suffered harsh times during covid-19, and it has characteristics of mean reversion with shocks having temporary effects. Furthermore, the research indicates that the stability of the Chinese stock market could continuously weaken [2].

COVID-19 has influenced not only China and Asian countries but also other countries around the world. Lee explores the correlation between COVID-19 sentiment and 11 select sector indices of the United States stock market from January 2020 to May 2020 and the predictability of the time series regression model using Daily News Sentiment Index and Google Trends data Fama-French three-factor model. The result reveals that communication services, consumer discretionary, industrial, energy, and material sectors are in the high-or middle-level correlation group while the utility sector is in the middle-or low-level correlation group. Financial, information technology, and health care sectors are in all three groups, but real estate and consumer staples sectors are only included in the middle-level correlation group. Additionally, the results demonstrate the industry return predictability [3]. Liammukda et al. represent the impact of COVID-19 on investors and the effect of the volatility of U.S. portfolios using Fama-French fivefactor models with the GARCH model and data from Google trend. The result is that COVID-19 will affect the volatility of big value portfolios, big growth portfolio, and small neutral portfolio, which is consistent with the 4 circuit breakers caused by the panic of investors [4]. He et al. mainly describe the impact of COVID-19 on the stock market. Their study shows different means and median in each index at different stages, calculating accurately and specifically. Moreover, there is an empirical result that is negative and the short-term effect in each country. Mathematical methods have been applied frequently in an article like mean, median, mean return, median return, etc. The result is that COVID-19 has a negative impact on the stock markets in the short run and bidirectional spill- over effects [5]. Aslam et al. assess how the COVID-19 affects the intraday multifractal properties of eight European stock markets by using five-minute index data ranging from 1 January 2020 to 23 March 2020. The Hurst exponents are calculated by applying multifractal detrended fluctuation analysis (MFDFA). Overall, the results confirm the existence of multifractality in European stock markets during the COVID-19 outbreak [6]. Kusumahadi and Permana aim to examine the influence of COVID-19 on stock return volatility using the TGARCH model with daily data of stock index returns for 15 countries from January 1, 2019, to June 30,2020 . The result of the research is that the exchange rate significantly impacts stock returns in most countries in the sample except for Morocco and the U.S, and volatility returns are positively affected by the domestic emergence of COVID-19 in the U.S, which means that stock return volatility tended to increase as the virus first occurred [7].

Other than the financial part of the impact of COVID-19, many other industries are affected as well. Ayati et al. find that short-term impacts of the COVID19 pandemic include demand changes, regulation revisions, research and development process changes, and the shift towards telecommunications and telemedicine. In addition, industry growth slow-down, and moved towards self-sufficiency in pharmaceutical production supply chain and trend changes in consumption of health-market products along with ethical dilemma could be anticipated as long-term impacts of COVID-19 pandemic on the pharmaceutical sector in global levels [8]. Hou and Chen used the Fama-French five-factor model to analyse the influence on the steel industry during covid 19 with the data from Kennethr, French data library. By selecting information of steel of 30 industry portfolios performed multiple linear regression, representing the fact that the steel industry has been negatively affected by the pandemic as a significant decline of production scale was seen. The research also reveals higher demand for a yield of investors, insensitive stock to the market, and inefficiency of RMW in the steel industry during covid19 [9]. Liu used the Fama-French five-factor model to investigate what impact has covid-19 bring to the service industry. Data from $08 / 16 / 2019$ to $03 / 10 / 2020$ was selected to compare the performance of the service industry. It illustrates that covid-19 had a negative effect on the service industry, there is a decrease in market valuation, and the public's expectation for this industry also became lower. In addition, the result also shows that businesses with aggressive investments are associated with returns. Large corporations perform better than small-scale businesses [10].

The predictability of the Fama-French model during the pandemic is also tested. Horváth and Wang evaluate the performance of Fama-French models on US stock markets during the COVID-19 using the Five-factor 
Fama-French model and the recursive robust IV algorithm in a GMM framework with data of 10 selected stocks from January 1990 till March 2020. The result is that all the beta model parameters are insignificant in the GMM model [11].

\subsection{Objective}

This study analyzes the impact of the COVID-19 on global stocks and especially on stocks in the clothing industry. Fama-French Five-Factor Model, which has highlighted that investors must be able to ride out the extra volatility and periodic underperformance that could occur in a short time, is used. At the same time, discovering what decisions companies were making before and after the COVID-19 and whether the firms' style of investment would change or not are included in this study. Generally, several celebrated companies will be selected as the research sample, which could promote data accuracy and persuasion.

\section{FAMA-FRENCH MODEL}

It is well-known that the inaccuracy of CAMP could result in a financial crisis. As there is a limitation of CAMP, Fama-French three-factor model is increasingly used. The formula of the Fama-French three-factor model is shown below:

$R_{i}-R_{f}=\beta_{M K T} \cdot\left(R_{m}-R_{f}\right)+\beta_{S M B} \cdot S M B+\beta_{H M L} \cdot$ $H M L$

In this model, $R_{i}$ refers to the expected rate of return; $R_{f}$ is the risk-free rate; $\mathrm{Rm}-\mathrm{Rf}$ is the market risk premium, the difference between the expected rate of return and the risk-free rate; SMB (small minus big) is the historic excess return gained by small-cap firms compared to high-capital firms; HML is the historic extra return acquired by value stocks compared to growth stocks. In addition, betas are different factor coefficients.

Later in 2015, the model is extended as Fama-French five-factor model, profitability, and investment was added into the model, which RMW and CMA express. RMW is the difference of return value of firms having high profitability and low profitability; CMA is the value of return gained by firms that invest more discreetly and tend to give up high-risk investments and firms making the aggressive investment. Fama and French constructed the new model with those five factors: $R_{i}-R_{f}=\beta_{M K T} \cdot\left(R_{m}-R_{f}\right)+\beta_{S M B} \cdot S M B+\beta_{H M L}$. $H M L+\beta_{R M W} \cdot R M W+\beta_{C M A} \cdot C M A$

This model can reflect the phenomenon that when the stock has relatively stronger cash flows, there would usually be an increase in return, which Fama-French three-factor model couldn't detect.

\section{RESULTS}

The data used in this study is the Fama-French 5 factors and the average value-weighted returns of thirty industry portfolios. All the data is recorded daily and is from the Kenneth R. French Data Library at Dartmouth College website. To compare the results before and during the epidemic, two sets of data are selected. Before February 2020, there were not many cases of COVID-19 in the United States, so data from February 1, 2019, to February 3, 2020, is used to represent the situation before COVID-19. As there have been many cases of the infection since March 2020, the data from March 2, 2020, to March 1, 2021, is used to stand for what happened during the pandemic in the U.S.

From the database, all the five factors and $R_{i}-R_{f}$ are obtained to create a Fama-French 5 factors model of the clothes industry before and during the pandemic. A t-test for slopes of multivariate regression is performed for the clothing industry. The results are shown in the two tables below.

Table 1. The predicted coefficients of the five factors and intercept before the pandemic and the corresponding t-statistics and P-value.

\begin{tabular}{|c|c|c|c|}
\hline Item & Coefficients & t Stat & P-valu \\
\hline Intercept & 0.002 & 0.053 & 0.95 \\
\hline MKT & 1.116 & 17.599 & 0.00 \\
\hline SMB & 0.144 & 1.452 & 0.14 \\
\hline HML & 0.149 & 1.508 & 0.13 \\
\hline RMW & 0.593 & 4.016 & 0.00 \\
\hline CMA & 0.001 & 0.004 & 0.99 \\
\hline \multicolumn{4}{|c|}{$\begin{array}{l}\text { Table 2. The predicted coefficients of the five fac } \\
\text { and intercept during the pandemic and the } \\
\text { corresponding t-statistics and P-value. }\end{array}$} \\
\hline Item & Coefficients & t Stat & P-value \\
\hline Intercept & 0.028 & 0.360 & 0.719 \\
\hline MKT & 0.966 & 24.932 & 0.000 \\
\hline SMB & 0.163 & 1.775 & 0.077 \\
\hline
\end{tabular}




\begin{tabular}{llll}
\hline HML & 0.297 & 3.938 & 0.000 \\
& & & \\
RMW & 0.211 & 1.368 & 0.172 \\
& & & \\
CMA & -0.527 & -3.054 & 0.003
\end{tabular}

As the tables above show, before COVID-19, three factors, SMB, HML, and CMA, were statistically insignificant, and the other two factors, which are MKT and RMW, were statistically significant. However, during the pandemic, the large P-values of SMB and RMW show that they are insignificant, and the other three factors are significant. In addition, the statistic of CMA was positive but become negative after the breakout of the pandemic.

\section{DISCUSSION}

\section{1. $M K T$}

The coefficient of MKT was greater than 1 before the pandemic. Still, after the break-out of COVID-19, the coefficient became smaller than 1 , which suggests the change in sensitivity of the market from sensitive to insensitive. The stock price of Nike decreased drastically to 66.79 in early March 2020, when the pandemic started. However, the stock price of the athletic-clothing brand returned to increase steadily in late March 2020 and has gained $40 \%$ in 2020 , and the S\&P 500 index showed that the percentage of increase and decrease was $-10.12 \%$, the amplitude was $28.47 \%$, and the maximum range was 2438.9. The data suggests that the company did suffer from store closures due to COVID-19, but it did not last long. We believe that the financial recovery that happened in the clothing industry is due to the development of online platforms and express delivery. Firms, including Nike, have been reducing their reliance on selling products through offline stores. The majority of consumers would use online shopping platforms to purchase their goods, which is more convenient and, more importantly, safer during the epidemic. Moreover, as people have to stay quarantined at home, they tend to spend more time on social media and other online platforms, including some shopping websites like Amazon, so people tend to buy more. Also, clothes are necessities for people, the demand for clothes would not decrease a lot because of the virus. In addition, the clothes market would still be able to provide enough products because most of the manufacturers are set in China, where the virus is under control. As a result, investors will expect the profits of the clothing industry to continue to grow.

\section{2. $S M B$}

The results of the data of SMB before and during COVID-19 are both insignificant. Although both SMB coefficients are positive and show that small-size stocks outperformed the bigger-size companies, the number is so small that there is only a little difference. The numbers demonstrate that the factor - "SMB" is redundant, and investors usually do not care too much about this factor in the clothing industry. Firstly, we think that small firms in the clothing market do not necessarily have significant disadvantages over large firms. The only difference is the strong connection to the supply chain. However, during the pandemic, the benefits of such a strong connection have decreased much. Moreover, small firms can also use online shopping platforms to offset that minor disadvantage. Second, consumers tend to buy clothes whose brands are familiar to them, which means that consumers are loyal to the brands they like in the clothing industry. Consumers' preferences are not directly related to the size of firms, so small clothes businesses can still make profits. The third reason is that investors would like to have the possibility of getting extremely good outcomes even the average returns are low, which is called the "lottery effect". Finally, small-size companies have a higher risk of assets reorganization or mergers, which would drastically increase the stock price. Hence, investors are willing to invest in small companies to make a considerable profit. As a result, people would not pay too much attention to the size premium factor while making investment decisions.

\section{3. $H M L$}

The HML factor was found statistically insignificant before the pandemic. It then became statistically significant under the influence of the epidemic, with a positive coefficient of 0.297. A positive coefficient indicates a higher tendency to invest in high book-tomarket stocks. The shares of the clothing companies were under-priced. The real value of their fundamentals is higher than the price.

As the coefficient was a positive 0.297 , investors are more likely to purchase high book-to-market stocks instead of low book-to-market stocks. During the pandemic, it's hard for the companies that have a lower book-to-market ratio to continue their growth. However, they have certain potential, in the epidemic, investors tend to invest in companies that have stable performance instead of firms that might grow better in the future, as the pandemic could have a huge negative effect on the global economy. Therefore, without $t$ the support of investors, the firms with a low book-tomarket ratio would have to face more problems, for instance, lack of sustainable motivation for growth. In this case, the large majority of people would have a 
negative attitude to companies having a low book-tomarket ratio, so the investors would tend to purchase the stock of those firms having high book-to-market ratio, at the same time, lots of low book-to-market stocks might experience a massive selling off during the epidemic.

\section{4. $R M W$}

The RMW factor was statistically significant before the pandemic. The coefficient was a positive 0.593, demonstrating that firms with higher profitability were better than firms with lower profitability. However, the RMW factor became insignificant in the period of COVID-19.

To tackle the problem of fewer salary got by people due to reduction of work hours, the large majority of people tend to save money instead of consuming them. Therefore, the global economy is suffering from the COVID-19 pandemic. The clothes industry is not excluded. During the pandemic, a large number of clothes retailers canceled their orders from factories as fewer people are making consumption. Although lots of work in progress was already done by the factories, some orders are completely finished. In this case, the clothing factories could only choose to store the goods produced in this period or to destroy them instead of getting profit from them.

Sales data from Amazon illustrates that the revenue earned by sales of clothes decreased by $40 \%$ on average during the pandemic, which means that it would be hard to pay for orders made to suppliers before. As a result, the profit gained by most companies in clothing industry would get much lower profit than before since many orders are cancelled in the pandemic, the factories had paid for the raw materials, fabric, capitals, work hours, and so on to produce the clothes ordered, nevertheless, the retailers refused to pay the production costs, triggering a decrease of profitability for most clothing companies, without the distinction of high-profitability companies or low-profitability companies before the pandemic. Therefore, the coefficient decreased.

\subsection{CMA}

CMA is the value of return gained by firms that invest more discreetly and give up high-risk investments and firms making aggressive investments. The coefficient of CMA was insignificant before the epidemic. However, the coefficient of CMA is significant and negative after the epidemic, indicating that investors tend to invest in aggressive companies. Companies that invest aggressively in an epidemic can expand their market share, and those that are good at expansion tend to have a better investment base. Before the outbreak of the epidemic, online entertainment methods such as live broadcasts were already popular. After the epidemic, live broadcast has transferred its role into another form, such as selling products. Many clothing brands have used the live broadcast to continue business to reduce the impact of the epidemic. Taking the brand Evly for example, there was 60 online live broadcast of the brand during the whole epidemic period, with a total broadcasting time of nearly 360 hours. The sales volume of the brand was about 20 million yuan in two months. At the same time, they invested more in live broadcast than past time, such as the cost of online propaganda and live broadcast. Inevitably, short video promotion and live broadcasts with goods can better improve users' shopping experience than traditional picture-based marketing. In the process of live broadcasting, the texture and colour details of clothing fabrics can be more truly presented to consumers.

\section{CONCLUSION}

This paper is based on the Fama-French five-factor model, studying the influence brought by COVID-19 on the clothing industry. It's proved that the pandemic definitely has a negative effect on the clothing industry due to the fact that the RMW factor decreased and became insignificant, illustrating that the return gained by corporations with robust profitability is lower than before in the clothing industry. Reversely, the HML factor is positive and became significant, which indicates a decrease in expectation of the performance of low book-to-market stocks. In addition, the CMA factor became significant. The coefficient decreased to a negative figure while it was positive before the epidemic, demonstrating that the investors have a higher tendency to purchase stocks of companies investing aggressively instead of firms investing conservatively under the influence of COVID-19. During the pandemic, investors should consider investing more in firms with high book-to-market ratios and tend to make aggressive investments. The purchase of stocks of firms having robust profitability should be considered carefully since the RMW factor shows that their profitability is decreasing.

\section{REFERENCES}

[1] Liu, H., Manzoor, A., Wang, C., Zhang, L., \& Manzoor, Z. (2020). The COVID-19 outbreak and affected countries stock markets response. International Journal of Environmental Research and Public Health, 17(8), 2800.

[2] Cristofaro, L., Gil-Alana, L. A., Chen, Z., \& Wanke, P. (2020). Modelling stock market data in China: Crisis and Coronavirus. Finance Research Letters, 101865.

[3] Lee, H. S. (2020). Exploring the Initial Impact of COVID-19 Sentiment on US Stock Market Using Big Data. Sustainability, 12(16), 6648. 
[4] Liammukda, A., Khamkong, M., Saenchan, L., \& Hongsakulvasu, N. (2020, September). Panic of COVID-19 on the volatility of US portfolios: Applied big data from Google trend. In 2020 1st International Conference on Big Data Analytics and Practices (IBDAP) (pp. 1-5). IEEE.

[5] He, Q., Liu, J., Wang, S., \& Yu, J. (2020). The impact of COVID-19 on stock markets. Economic and Political Studies, 8(3), 275-288.

[6] Aslam, F., Mohti, W., \& Ferreira, P. (2020). Evidence of intraday multifractality in European stock markets during the recent coronavirus (COVID-19) outbreak. International Journal of Financial Studies, 8(2), 31.

[7] Kusumahadi, T. A., \& Permana, F. C. (2021). Impact of COVID-19 on Global Stock Market Volatility. Journal of Economic Integration, 36(1), $20-45$.

[8] Ayati, N., Saiyarsarai, P., \& Nikfar, S. (2020). Short- and long-term impacts of COVID-19 on the pharmaceutical sector. DARU Journal of Pharmaceutical Sciences, 28(2), 799-805.

[9] Hou, D., \& Chen, Z. (2021, April). Research on the application of Fama-French 5-factor model in the steel industry during COVID-19. In Journal of Physics: Conference Series (Vol. 1865, No. 4, p. 042104). IOP Publishing.

[10] Liu, S. (2020, December). Analysis of COVID-19 on Service Industry Based on Fama and French Five-Factor Model. In 2020 Management Science Informatization and Economic Innovation Development Conference (MSIEID) (pp. 154-157). IEEE.

[11] Horváth, D., \& Wang, Y. L. (2020). The examination of Fama-French Model during the Covid-19. Finance Research Letters, 101848. 